\title{
Water Extracts of Hull-less Waxy Barley (Hordeum vulgare L.) Cultivar 'Boseokchal' Inhibit RANKL-induced Osteoclastogenesis
}

\author{
Kwang-Jin Kim ${ }^{1}$, Yongjin Lee ${ }^{1}$, So-Ri Son ${ }^{2}$, Hyunjin Lee ${ }^{3}$, Young-Jin Son ${ }^{1, *}$, \\ Mi-Kyung Lee ${ }^{4, * \mathbb{D}}$ and Mija Lee ${ }^{3, * \mathbb{D}}$ \\ 1 Department of Pharmacy, Sunchon National University, Suncheon 57922, Korea; \\ mastiffk@naver.com (K.-J.K.); yojilee@gmail.com (Y.L.) \\ 2 Department of Biomedical Science and technology, Graduate School, Kyung Hee University, Seoul 02447, \\ Korea; allosori@khu.ac.kr \\ 3 Department of Crop Foundation, National Institute of Crop Science (NICS), Rural Development \\ Administration (RDA), Wanju 55365, Korea; poi7346@korea.kr \\ 4 Department of Food and Nutrition, Sunchon National University, Jeonnam, Suncheon 57922, Korea \\ * Correspondence: sony@sunchon.ac.kr (Y.-J.S.); leemk@scnu.ac.kr (M.-K.L.); esilvia@korea.kr (M.L.); \\ Tel.: +82-61-750-3755 (Y.-J.S.); +82-61-750-3656 (M.-K.L.); +82-63-238-5332 (M.L.)
}

Received: 11 September 2019; Accepted: 15 October 2019; Published: 16 October 2019

\begin{abstract}
Osteoporosis is a disease that leads to reduced bone mineral density. The increase in patient and medical costs because of global aging is recognized as a problem. Decreased bone mass is a common symptom of bone diseases such as Paget's disease, rheumatoid arthritis, and multiple myeloma. Osteoclasts, which directly affect bone mass, show a marked increase in differentiation and activation in the aforementioned diseases. Moreover, these multinucleated cells made from monocytes/macrophages under the influence of RANKL and M-CSF, are the only cells capable of resorbing bones. In this study, we found that the water extracts of Boseokchal (BSC-W) inhibited osteoclast differentiation in vitro and investigated its inhibitory mechanism. BSC-W was obtained by extracting flour of Boseokchal using hexane and water. To osteoclast differentiation, bone marrow-derived macrophage cells (BMMs) were cultured with the vehicle $(0.1 \%$ DMSO) or BSC-W in the presence of M-CSF and RANKL for 4 days. Cytotoxicity was measured by CCK-8. Gene expression of cells was confirmed by real-time PCR. Protein expression of cells was observed by western blot assay. Bone resorption activity of osteoclast evaluated by bone pit formation assay using an Osteo Assay Plate. BSC-W inhibited RANKL-induced osteoclastogenesis in a dose-dependent manner without exerting a cytotoxic effect on BMMs. BSC-W decreased the transcriptional and translational expression of c-Fos and NFATc1, which are regulators of osteoclastogenesis and reduced the mRNA expression level of TRAP, DC-STAMP, and cathepsin K, which are osteoclast differentiation marker. Furthermore, BSC-W reduced the resorption activity of osteoclasts. Taken together, our results indicate that BSC-W is a useful candidate for health functional foods or therapeutic agents that can help treat bone diseases such as osteoporosis.
\end{abstract}

Keywords: osteoporosis; bone; osteoclast; barley; extracts; NFATc1

\section{Introduction}

Bones are dynamic tissues of various types of cells that undergo regeneration and repair processes known as bone remodeling. Osteoclasts and osteoblasts are cells that play an important role in bone maintenance [1], and the balance between osteoclastic and osteoblastic activity is important to maintenance 
of bone homeostasis. Increased numbers or activity of osteoclasts in bone homeostasis causes bone loss in diseases such as osteoporosis, Paget's disease, rheumatoid arthritis, and periodontal disease [2].

Osteoporosis, which is the most common bone disease in the world, is associated with bone mass decrease and fracture risk. Patients with osteoporosis have a low bone density and weakened microstructure, which is likely to lead to pathological fractures. Fractures caused by osteoporosis are recognized as a global public health problem [3]. Such fractures can cause considerable pain and severe disability, leading to poor quality of life. The main cause of osteoporosis is related to increased osteoclast numbers and their bone resorption activity [3].

Osteoclasts are tartrate-resistant acid phosphatase-positive multinuclear cells (TRAP ${ }^{+}$-MNCs) formed by the fusion of several mononuclear precursors that are responsible for bone resorption. Osteoclasts remove old or weak bones, and are involved in maintenance of blood mineral levels [4,5]. Osteoclast differentiation is regulated by two cytokines, macrophage colony stimulating factor (M-CSF) and receptor activator of nuclear factor- $\mathrm{kB}(\mathrm{NF}-\mathrm{kB}$ ) ligand (RANKL) [6]. M-CSF produced by osteoblasts (or immune cells) induces the expression of RANK and the survival signal of osteoclasts in osteoclast precursor cells [7]. RANKL secreted by osteoblast/activated T cells binds to the osteoclast receptor RANK and induces the activation of mitogen-activated protein kinase (MAPK), c-Fos, and NFATc1 [5,6,8-10]. NFATc1, the key transcription factor for osteoclast formation, regulates the expression of osteoclast differentiation and activation factors such as TRAP, cathepsin K, and dendritic cell-specific transmembrane protein (DC-STAMP) [11-15].

Studies of the development of fruit or grains containing functional ingredients and antioxidants have been conducted by many researchers all over the world. Anthocyanin is known to be an antioxidant with antidiabetic activity, as well as cholesterol lowering, anticancer, and anti-aging effects [16-19]. Recently, Boseokchal was developed as a new barley strain with a high content of anthocyanin [20,21]. In this study, we investigated the effects of Boseokchal extract on osteoclast differentiation and activation directly related to osteoporosis.

\section{Results}

\subsection{BSC-W Inhibited RANKL-Mediated Osteoclast Differentiation}

To examine whether BSC-W affected RANKL-mediated osteoclastogenesis, BMMs were cultured with RANKL and M-CSF in the presence of $0.1 \%$ DMSO (vehicle) or BSC-W $(0,1,3,10,30 \mu \mathrm{g} / \mathrm{mL}$ ) for 4 days. BMMs were differentiated into TRAP ${ }^{+}-\mathrm{MNC}$ by RANKL, but BSC-W significantly reduced this differentiation (Figure 1A). When the number of $\mathrm{TRAP}^{+}-\mathrm{MNC}$ with three or more nuclei was analyzed, the formation of osteoclasts was significantly decreased at a BSC-W concentration of more than $10 \mu \mathrm{g} / \mathrm{mL}$ (Figure 1B).

\subsection{BSC-W Had No Cytotoxic Effect On Bmms}

To determine whether inhibition of osteoclastogenesis was due to cytotoxicity by BSC-W, we conducted cytotoxicity studies in BMMs. Briefly, BMMs were cultured in 10\% $\alpha$-MEM treated with 0.1\% DMSO (vehicle) or BSC-W $(1,3,10,30 \mu \mathrm{g} / \mathrm{mL})$ for 3 days in the presence of $30 \mathrm{ng} / \mathrm{mL}$ M-CSF. As shown in Figure $1 \mathrm{C}$, BSC-W did not exert cytotoxicity toward BMMs at the concentrations used in this study (Figure 1C).

\subsection{Effects of BSC-W on RANKL-Induced Gene Expression}

To confirm the mechanism of inhibition activity of BSC-W in osteoclast differentiation, we analyzed the expression of c-Fos and NFATc1, transcription factors that regulates osteoclastogenesis, and the marker genes involved in osteoclast differentiation, such as TRAP, DC-STAMP, and cathepsin K. RANKL increased the level of mRNA expression of c-Fos and NFATc1, but BSC-W significantly decreased their expression level (Figure 2A,B). BSC-W also significantly reduced the mRNA expression level of TRAP, DC-STAMP, and cathepsin K (Figure 2C-E). 
A

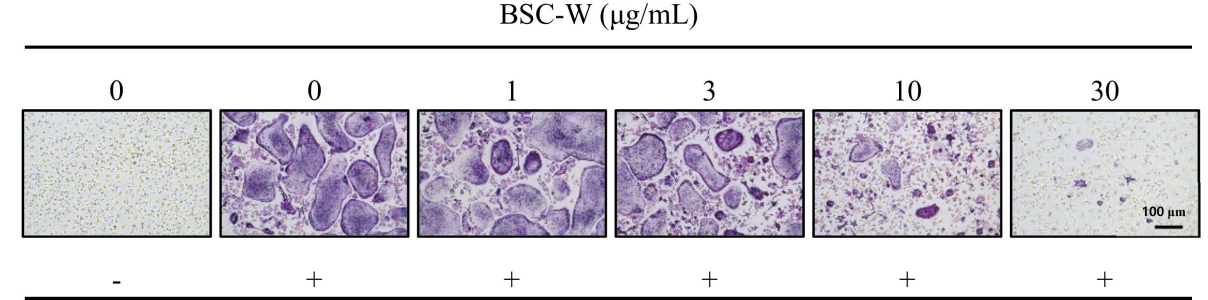

RANKL (10 ng/mL)

B

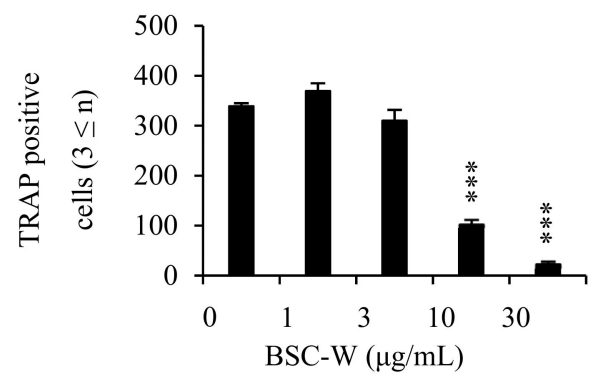

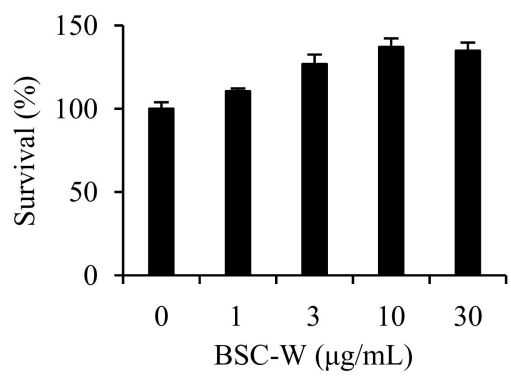

Figure 1. BSC-W inhibited osteoclast differentiation. (A) BMMs were cultured with $10 \mathrm{ng} / \mathrm{mL}$ RANKL and $30 \mathrm{ng} / \mathrm{mL}$ M-CSF for 4 days in the presence of vehicle $(0.1 \% \mathrm{DMSO})$ or the indicated concentrations of BSC-W. Cells were fixed in 3.7\% formalin, permeabilized with $0.1 \%$ Triton X-100, and stained with TRAP solution. (B) TRAP-positive multinucleated cells (3 or more nuclei) were counted as osteoclasts. ${ }^{* * *} p<0.001(n=3)$. (C) BMMs were cultured with $30 \mathrm{ng} / \mathrm{mL}$ M-CSF for 3 days in the presence of vehicle $(0.1 \%$ DMSO) or the indicated concentrations of BSC-W. The effects of BSC-W on BMMs viability were assessed using a CCK-8 assay kit $(n=3)$.

A

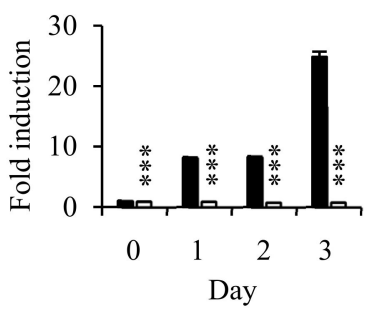

D

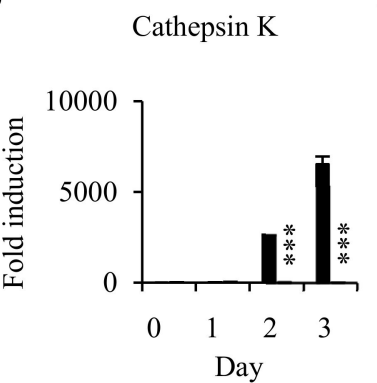

B

c-Fos

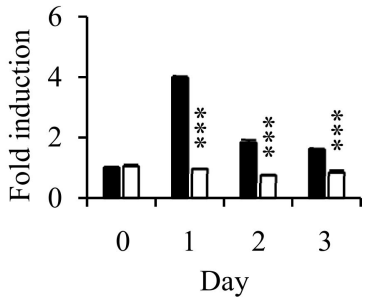

DC-STAMP

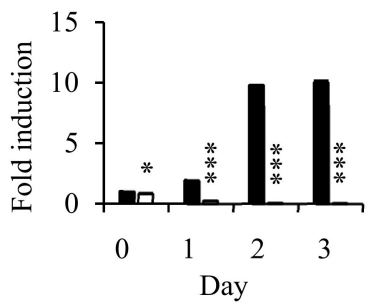

C

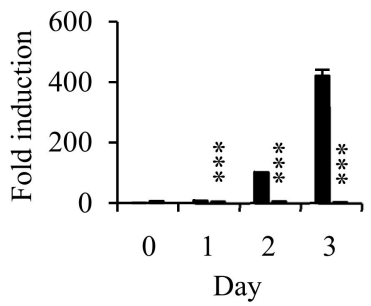

$0.1 \%$ DMSO

BSC-W $(30 \mu \mathrm{g} / \mathrm{mL})$

Figure 2. Effects of BSC-W on RANKL-mediated mRNA expression of NFATc1. BMMs were treated with vehicle $(0.1 \%$ DMSO) or BSC-W $(30 \mu \mathrm{g} / \mathrm{mL})$ and $30 \mathrm{ng} / \mathrm{mL} \mathrm{M-CSF}$ for $1 \mathrm{~h}$ and then $10 \mathrm{ng} / \mathrm{mL}$ RANKL at the indicated times. Total RNA was subsequently isolated using TRIzol reagent, after which the mRNA expression levels were evaluated by real-time PCR. (A) NFATc1, (B) c-Fos, (C) TRAP, (D) Cathepsin K, and (E) DC-STAMP were used. Glyceraldehyde-3-phosphate dehydrogenase (GAPDH) was used as the internal control. ${ }^{*}, p<0.05 ;{ }^{* *}, p<0.001$. 


\subsection{BSC-W Inhibited RANKL-Induced Protein Expression of NFATc1}

We confirmed the effects of BSC-W on protein expression of c-Fos and NFATc1 using Western blot analysis. The protein expression of c-Fos and NFATc1 induced by RANKL was significantly decreased by BSC-W (Figure 3). These results indicated that BSC-W inhibited NFATc1 expression and osteoclast formation.

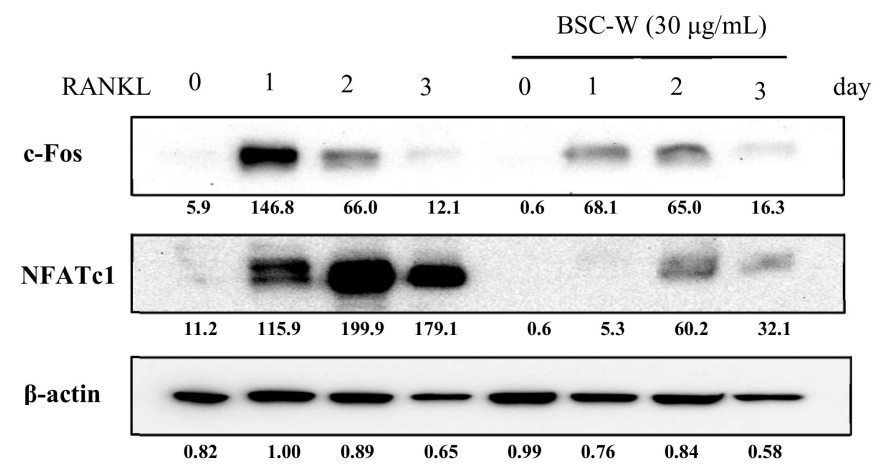

Figure 3. BSC-W decreases RANKL-mediated protein expression of NFATc1. BMMs were pretreated with vehicle $(0.1 \%$ DMSO) or BSC-W $(30 \mu \mathrm{g} / \mathrm{mL})$ and $30 \mathrm{ng} / \mathrm{mL} \mathrm{M-CSF} \mathrm{for} 1 \mathrm{~h}$ prior to $10 \mathrm{ng} / \mathrm{mL}$ RANKL stimulation at the indicated times. Cell lysates were resolved by SDS-PAGE, and western blotting was performed with anti-c-Fos, anti-NFATc1, and anti-actin antibodies as indicated. The above figures of c-Fos and NFATc1 were calibrated based on the loading amounts of $\beta$-actin.

\subsection{Effects of BSC-W on RANKL-Mediated Bone Resorptive Activity of Osteoclasts}

We investigated whether BSC-W affects bone resorption of osteoclasts. The osteoclasts made a wide pit area on the bone slice, but BSC-W drastically reduced the pit area in a dose-dependent manner (Figure 4).

A

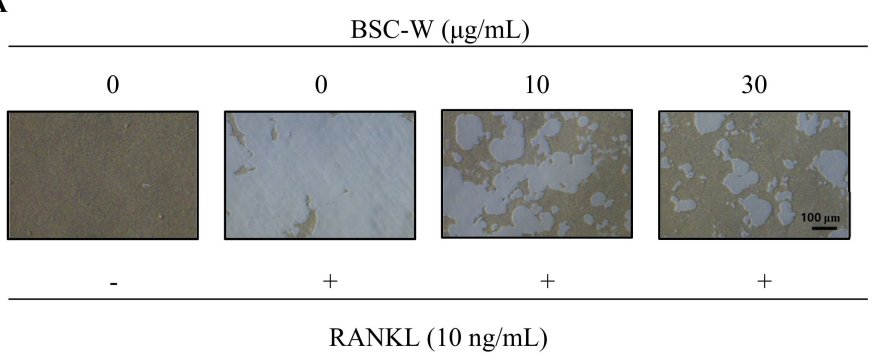

B

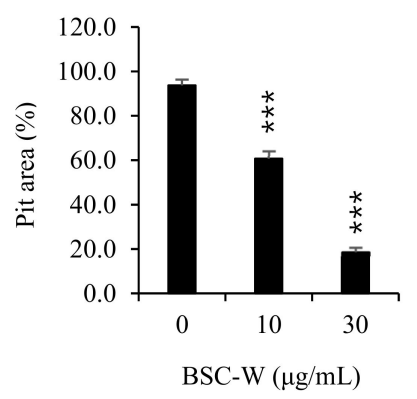

Figure 4. BSC-W inhibited bone resorption by RANKL-induced osteoclasts. (A) BMMs were plated on an Osteo Assay Plate and treated with $30 \mathrm{ng} / \mathrm{mL}$ M-CSF and $10 \mathrm{ng} / \mathrm{mL}$ RANKL in the presence of different concentrations of BSC-W. After 4 days of culture, the cells attached to the Osteo Assay Plate were removed and photographed under a light microscope. (B) Pit areas were quantified using the Image J program. ${ }^{* * *} p<0.001(n=3)$. 


\section{Discussion}

Osteoporosis is a disease in which the quality of the bone deteriorates and fracture rate increases. In 2000, a total of 9 million osteoporotic fractures occurred, including 1.6 million pelvic fractures, 1.7 million forearm fractures, and 1.4 million vertebral fractures [22]. The increase in osteoporosis patients because of population aging has become a problem for the health and economy of the world [23,24]; therefore, investigation of osteoporosis is necessary for the prevention and treatment of osteoporosis.

Bone quality is greatly influenced by the balance between the activity of bone-resorbing osteoclasts and bone-forming osteoblasts. Osteoclasts, which originate from mononuclear cells/macrophages of bone marrow, are the only cells that can absorb bone [25]. These cells are produced and matured through various steps, such as differentiation and fusion, and the overall process is regulated by the RANKL-RANK signaling system [5]. Specifically, RANKL-RANK signaling is important to the formation of osteoclasts and for the treatment of pathological bone loss by these cells. After RANKL binds to the receptor, RANK, it rapidly activates MAPKs signaling molecules, such as p38, ERK, and JNK, and eventually promotes the activation of c-Fos-NFATc1 signaling, which is known to be an important transcription factor in osteoclast differentiation and activation [26-28].

Barley, which seems to have been cultivated in the Mesopotamia region since $7000 \mathrm{BC}$, is one of the major grains, along with rice, wheat, sorghum, and corn. Barley and wheat are believed to be the first crops grown by humans. In the previous studies, $\beta$-D-glucan, a representative dietary fiber of barley, decreased blood cholesterol levels in the body $[29,30]$. The value of barley as a healthy food is gradually increasing because of its excellent nutritional materials. The Boseokchal used in this study is an improved strain of hull-less waxy barley that contains high levels of the antioxidant anthocyanin and has therefore attracted attention as a functional food.

Here, we investigated the effects of Boseokchal's water extract (BSC-W) on RANKL-induced osteoclastogenesis. BSC-W significantly reduced the differentiation of RANKL-treated macrophages into osteoclasts with no cytotoxicity, confirming that it inhibited osteoclast formation. Transcriptional factors of the NFAT family are known for being key molecules involved in the regulation of various biological systems, as well as in the formation of osteoclasts [31-34]. Therefore, we analyzed the expression levels of NFATc1 mRNA and protein by real-time PCR and western blotting, respectively, to check the influence of BSC-W against osteoclast differentiation. BSC-W significantly inhibited the expression levels of RANKL-induced NFATc1 mRNA and protein during osteoclast differentiation. In addition, mRNA expression of TRAP, DC-STAMP, and cathepsin K, which are differentiation/activation markers of osteoclasts, were significantly decreased by BSC-W. We also confirmed that the bone resorptive activity of osteoclasts was inhibited by BSC-W using a pit assay.

In previous papers, polyphenols and flavonoids, which are the major components of plant extracts, they are known as the inhibitive materials against osteoclast differentiation in osteoporosis. So it would be helpful in the treatment of osteoporosis [35-40]. According to the results of analyzing the contents of polyphenol and flavonoid component in BSC-W, the total polyphenol content was $8.73 \pm 0.05 \mathrm{mg}$ gallic acid equivalents/g and the total flavonoid content was $41.27 \pm 1.46 \mathrm{mg}$ quercetin equivalents/g. Therefore, it was confirmed that the inhibitive activity of BSC-W against the differentiation and resorption of osteoclasts caused by polyphenols and flavonoids.

Taken together, these results suggested that BSC-W could prevent osteoclast differentiation by inhibiting the expression of NFATc1 and the activities of osteoclastogenic-related factors during osteoclast formation and differentiation. Therefore, BSC-W could be applied as a useful functional food or therapeutic agent for bone diseases such as osteoporosis. 


\section{Materials and Methods}

\subsection{Preparation of the Boseokchal Water Extract}

Preparation of Boseokchal water extract was performed as previously described [41]. Briefly, flour of Boseokchal was defatted three times with $1 \mathrm{~L}$ hexane for $24 \mathrm{~h}$ at room temperature. After filtration with Whatman No. 3, the residue was extracted three times with $1 \mathrm{~L}$ prethanol, then passed through a Büchner funnel lined with filter paper (Carl Roth, Karlsruhe, Germen, 111A, Ø100 mm). The residue of the prethanol extraction was subsequently extracted twice with $1 \mathrm{~L}$ of water for $24 \mathrm{~h}$ at room temperature, after which the liquid was concentrated on a rotary evaporator and lyophilized to give an extract. The total flavonoid and phenolic contents of BSC-W was analyzed by the method of previous papers $[42,43]$.

\subsection{Cell Culture and Osteoclast Differentiation}

In vitro cell experiments were performed as previously published paper [44]. All cells were cultured at $37{ }^{\circ} \mathrm{C}$ under $5 \% \mathrm{CO}_{2}$ and medium was renewed every three days. Bone marrow cells (BMCs) were obtained from the femurs and tibiae of five week-old male ICR mice $(n=2$ : Raon Bio, Yongin, Korea). The protocol was approved by the Sunchon National University Institutional Animal Care and Use Committee (SCNUIACUC; Permit No. SCNU IACUC 2016-06). The BMCs from mice were cultured with $10 \mathrm{ng} / \mathrm{mL}$ macrophage colony-stimulating factor (M-CSF; Peprotech, Rocky Hill, NJ, USA) overnight in $\alpha$-MEM (Thermo Fisher Scientific Inc., Waltham, MA, USA) containing 10\% fetal bovine serum (FBS; Thermo Fisher Scientific Inc., Waltham, MA, USA) and $100 \mathrm{U} / \mathrm{mL}$ penicillin/streptomycin (10\% FBS $\alpha$-MEM) on two $10 \mathrm{~cm}$ culture dish. Non-adherent cells were isolated and cultured with M-CSF (30 ng/mL) in 10\% FBS $\alpha$-MEM on $10 \mathrm{~cm}$ Petri dishes for three days. Adhered cells were used as bone marrow derived macrophages (BMMs). We used the 96 well plate and cells were plated $1 \times 10^{4}$ cells/well. BMMs were cultured with RANKL (10 ng/mL; R\&D Systems, Minneapolis, MN, USA) and M-CSF (30 ng/mL) in 10\% FBS $\alpha$-MEM for 4 days in the presence of vehicle or BSC-W with $0.1 \%$ DMSO as solvent.

\subsection{Tartrate-Resistant Acid Phosphatase (TRAP) Staining}

The cells were fixed with formaldehyde (10\%) for $5 \mathrm{~min}$, permeabilized with Triton X-100 (0.1\%) for $10 \mathrm{~min}$, and then incubated with TRAP solution (Sigma-Aldrich, St. Louis, MO, USA) at room temperature for $10 \mathrm{~min}$. Red stained cells with three or more nuclei were counted as mature osteoclasts.

\subsection{Cytotoxicity Assay for Extracts of BSC-W}

BMMs were incubated with M-CSF (30 ng/mL) in 10\% FBS $\alpha$-MEM in the presence of 0.1\% DMSO or BSC-W for 3 days. Cell viability was assessed using a cell counting kit-8 (CCK-8; Dojindo Molecular Technologies, Kumamoto, JP) according to the manufacturer's protocols.

\subsection{Real-Time PCR}

Real-time PCR was performed as previously described [26]. BMMs were cultured with RANKL $(10 \mathrm{ng} / \mathrm{mL})$ and M-CSF $(30 \mathrm{ng} / \mathrm{mL})$ in $10 \%$ FBS $\alpha$-MEM for $0,1,2$, or 3 days in the presence of $0.1 \%$ DMSO or BSC-W. For real-time PCR, primer sets were designed (Table 1) using the online primer3 program [45]. Total RNA was isolated using TRIzol reagent (Thermo Fisher Scientific Inc., Waltham, MA, USA) according to the manufacturer's protocols. cDNA was synthesized using a M-MLV cDNA synthesis kit (Enzynomics, Daejeon, Korea) according to the manufacturer's protocols. QPCR was conducted using the TOPreal qPCR 2× PreMIX (BioRad, Hercules, CA, USA) in a Real-Time PCR Detection System (BioRad, Hercules, CA, USA). The mRNA levels of the genes were analyzed by the $2^{-\Delta \Delta C T}$ method [46]. Glyceraldehyde-3-phosphate dehydrogenase (GAPDH) was used as an internal standard. 
Table 1. Primer sequences used in this study.

\begin{tabular}{|c|c|c|}
\hline \multirow{2}{*}{ Gene of Interest } & \multicolumn{2}{|c|}{ Primer Sequence $\left(5^{\prime} \rightarrow 3^{\prime}\right)$} \\
\hline & Sense & Anti-Sense \\
\hline NFATc1 & GGGTCAGTGTGACCGAAGAT & GGAAGTCAGAAGTGGGTGGA \\
\hline c-Fos & CCAGTCAAGAGCATCAGCAA & AAGTAGTGCAGCCCGGAGTA \\
\hline Cathepsin K & GGCCAACTCAAGAAGAAAAC & GTGCTTGCTTCCCTTCTGG \\
\hline DC-STAMP & CCAAGGAGTCGTCCATGATT & GGCTGCTTTGATCGTTTCTC \\
\hline TRAP & GATGACTTTGCCAGTCAGCA & ACATAGCCCACACCGTTCTC \\
\hline GAPDH & AACTTTGGCATTGTGGAAGG & ACACATTGGGGGTAGGAACA \\
\hline
\end{tabular}

\subsection{Western Blot}

Western blotting was conducted as previously described [47]. Briefly, BMMs were incubated in the same manner as real-time PCR assays, after which cells were washed with phosphate-buffered saline (PBS) and lysed in lysis buffer ( $50 \mathrm{mM}$ Tris- $\mathrm{HCl}, 150 \mathrm{mM} \mathrm{NaCl}, 5 \mathrm{mM}$ EDTA, 1\% Triton X-100, $1 \mathrm{mM}$ sodium fluoride, $1 \mathrm{mM}$ sodium vanadate, and $1 \%$ deoxycholate) containing protease inhibitors. Next, the supernatant containing proteins were subjected to $10 \%$ sodium dodecyl sulfate-polyacrylamide gel electrophoresis (SDS-PAGE). Separated proteins were subsequently transferred to a polyvinylidene difluoride (PVDF) membrane (Millipore Corporation, Billerica, MA, USA), after which membranes were blocked with 5\% skim milk in TBST (10 mM Tris- $\mathrm{HCl} \mathrm{pH} \mathrm{7.5,} 150 \mathrm{mM} \mathrm{NaCl}$, and $0.1 \%$ Tween 20) for $1 \mathrm{~h}$ at room temperature. Blocked membranes were then incubated overnight at $4{ }^{\circ} \mathrm{C}$ with a primary antibody, after which they were incubated with secondary antibody conjugated to horseradish peroxidase for $2 \mathrm{~h}$ at room temperature. Finally, the membranes were developed with CLARO ${ }^{\mathrm{TM}}$ Mucho (bio-D, Gwangmyeong, Korea) using the LAS-4000 luminescent image analyzer (Fuji Photo Film Co. Ltd., Tokyo, JP).

\subsection{Bone Pit Formation Assay}

BMMs were cultured with RANKL (10 ng/mL) and M-CSF (30 ng/mL) in 10\% FBS $\alpha$-MEM for 3 days and then treated with vehicle (0.1\% DMSO) or BSC-W for additional 3 days on an Osteo Assay Plate (24 well plate; Corning Inc., Corning, NY, USA) at a density of $6 \times 10^{4}$ cells/well. Cells were removed with sodium hypochlorite (5\%) for $5 \mathrm{~min}$, after which the pit area was observed under a light microscope (magnification, 50x; Leica Microsystems, Wetzlar, Germany) and measured using the Image J software (NIH, Bethesda, MD, USA).

\subsection{Statistical Analysis}

All quantitative data are presented as the means \pm standard deviations of three replicate experiments. The treatment groups were compared individually with the control group. Statistical differences were identified by Student's t-tests and probability $(p)$ values $<0.05$ were considered significant $\left(p\right.$-values ${ }^{*}<0.05$, ** $<0.01$, and $\left.{ }^{* * *}<0.001\right)$.

\section{Conclusions}

The water extract of Boseokchal (BSC-W) inhibited osteoclast differentiation by blocking the expression of NFATc1 during RANKL-induced osteoclastogenesis. It was also confirmed that the expression levels of osteoclast differentiation/activation factors, such as TRAP, DC-STAMP, and cathepsin K, decreased with the decreased expression of NFATc1 by BSC-W. Therefore, BSC-W could be a useful functional food or a therapeutic agent for treatment of bone diseases such as osteoporosis.

Author Contributions: Conceived and designed the study: K.-J.K., Y.L., Y.-J.S., M.-K.L. Performed the study: K.-J.K., Y.L., S.-R.S., H.L. Analyzed the data: K.-J.K., M.-K.L., M.L. Wrote the paper: K.-J.K., Y.L., Y.-J.S. All authors read and approved the final manuscript. 
Funding: This work was supported by the Cooperative Research Program for Agriculture Science and Technology Development (Project No. PJ013524022018). The funder had no role in experiment and data analysis, decision to publish, or preparation of manuscript.

Acknowledgments: Thank you for supplying extracts used in osteoporosis experiments. The water extract of Boseokchal (BSC-W) was supplied by the National Institute of Crop Science.

Conflicts of Interest: The authors declare no conflict of interest.

\section{References}

1. Goltzman, D. Discoveries, drugs and skeletal disorders. Nat. Rev. Drug Discov. 2002, 1, 784-796. [CrossRef] [PubMed]

2. Rodan, G.A. Therapeutic Approaches to Bone Diseases. Science 2000, 289, 1508-1514. [CrossRef] [PubMed]

3. NIH Consensus Development. Osteoporosis prevention, diagnosis, and therapy. JAMA 2000, 285, 785-795.

4. Vaananen, H.K.; Laitala-Leinonen, T. Osteoclast lineage and function. Arch. Biochem. Biophys. 2008, 473, 132-138. [CrossRef]

5. Boyle, W.J.; Simonet, W.S.; Lacey, D.L. Osteoclast differentiation and activation. Nature 2003, 423, $337-342$. [CrossRef]

6. Feng, X. RANKing Intracellular Signaling in Osteoclasts. IUBMB Life 2005, 57, 389-395. [CrossRef]

7. Kansara, M.; Teng, M.W.; Smyth, M.J.; Thomas, D.M. Translational biology of osteosarcoma. Nat. Rev. Cancer 2014, 14, 722-735. [CrossRef]

8. Galibert, L. The Involvement of Multiple Tumor Necrosis Factor Receptor (TNFR)-associated Factors in the Signaling Mechanisms of Receptor Activator of NF-kappa B, a Member of the TNFR Superfamily. J. Boil. Chem. 1998, 273, 34120-34127. [CrossRef]

9. Wong, B.R.; Josien, R.; Lee, S.Y.; Vologodskaia, M.; Steinman, R.M.; Choi, Y. The TRAF family of signal transducers mediates NF-kappaB activation by the TRANCE receptor. J. Boil. Chem. 1998, 273, 28355-28359. [CrossRef]

10. Teitelbaum, S.L. RANKing c-Jun in osteoclast development. J. Clin. Investig. 2004, 114, 463-465. [CrossRef]

11. Takayanagi, H. The Role of NFAT in Osteoclast Formation. Ann. New York Acad. Sci. 2007, 1116, $227-237$. [CrossRef] [PubMed]

12. Takayanagi, H. Osteoimmunology: Shared mechanisms and crosstalk between the immune and bone systems. Nat. Rev. Immunol. 2007, 7, 292-304. [CrossRef] [PubMed]

13. Wagner, E.F.; Eferl, R. Fos/AP-1 proteins in bone and the immune system. Immunol. Rev. 2005, 208, $126-140$. [CrossRef] [PubMed]

14. Matsumoto, M.; Kogawa, M.; Wada, S.; Takayanagi, H.; Tsujimoto, M.; Katayama, S.; Hisatake, K.; Nogi, Y. Essential Role of p38 Mitogen-activated Protein Kinase in Cathepsin K Gene Expression during Osteoclastogenesis through Association of NFATc1 and PU.1. J. Boil. Chem. 2004, 279, 45969-45979. [CrossRef] [PubMed]

15. Yagi, M.; Miyamoto, T.; Sawatani, Y.; Iwamoto, K.; Hosogane, N.; Fujita, N.; Morita, K.; Ninomiya, K.; Suzuki, T.; Miyamoto, K.; et al. DC-STAMP is essential for cell-cell fusion in osteoclasts and foreign body giant cells. J. Exp. Med. 2005, 202, 345-351. [CrossRef] [PubMed]

16. Hyun, J.W.; Chung, H.S. Cyanidin and Malvidin from Oryza sativa cv. Heugjinjubyeo mediate cytotoxicity against human monocytic leukemia cells by arrest of G(2)/M phase and induction of apoptosis. J. Agric. Food Chem. 2004, 52, 2213-2217. [CrossRef]

17. Ryu, S.; Han, S.; Park, S.; Kim, H. Antioxidant activity of blackish purple rice. Korean J. Crop. Sci. 2006, 51, 173-178.

18. Ghosh, M.; Kim, I.S.; Lee, Y.M.; Hong, S.M.; Lee, T.H.; Lim, J.H.; Debnath, T.; Lim, B.O. The Effects of Aronia melanocarpa 'Viking' Extracts in Attenuating RANKL-Induced Osteoclastic Differentiation by Inhibiting ROS Generation and c-FOS/NFATc1 Signaling. Molecules 2018, 23, 615. [CrossRef]

19. Dou, C.; Li, J.; Kang, F.; Cao, Z.; Yang, X.; Jiang, H.; Yang, B.; Xiang, J.; Xu, J.; Dong, S. Dual Effect of Cyanidin on RANKL-Induced Differentiation and Fusion of Osteoclasts. J. Cell Physiol. 2016, 231, 558-567. [CrossRef]

20. Choi, J.; Suh, J.; Min, K.; Lee, M.; Park, J.; Kim, Y.; Park, T.; Hwang, J.; Kim, H.; Baek, S.; et al. A new colored naked barley cultivar" Zasoojeongchal" with waxy endosperm. Korean J. Breed. Sci. 2007, 39, 244-245. 
21. Lee, M.; Kim, Y.; Park, J.; Kim, M.; Hyun, J. Hull-less waxy barley (Hordeum vulgare L.) cultivar 'Boseokchal' with high anthocyanin content and purple lemma. Korean J. Breed. Sci. 2014, 46, 456-462. [CrossRef]

22. Wang, Y.; Harding, S.V.; Thandapilly, S.J.; Tosh, S.M. Jones PJH, Ames NP. Barley beta-glucan reduces blood cholesterol levels via interrupting bile acid metabolism. Br. J. Nutr. 2017, 118, 822-829. [CrossRef] [PubMed]

23. Crabtree, G.R.; Olson, E.N. NFAT signaling: Choreographing the social lives of cells. Cell 2002, 109, 67-79. [CrossRef]

24. Takayanagi, H.; Kim, S.; Koga, T.; Nishina, H.; Isshiki, M.; Yoshida, H.; Saiura, A.; Isobe, M.; Yokochi, T.; Inoue, J.-I.; et al. Induction and Activation of the Transcription Factor NFATc1 (NFAT2) Integrate RANKL Signaling in Terminal Differentiation of Osteoclasts. Dev. Cell 2002, 3, 889-901. [CrossRef]

25. Hogan, P.G.; Chen, L.; Nardone, J.; Rao, A. Transcriptional regulation by calcium, calcineurin, and NFAT. Genes Dev. 2003, 17, 2205-2232. [CrossRef]

26. Asagiri, M.; Sato, K.; Usami, T.; Ochi, S.; Nishina, H.; Yoshida, H.; Morita, I.; Wagner, E.F.; Mak, T.W.; Serfling, E.; et al. Autoamplification of NFATc1 expression determines its essential role in bone homeostasis. J. Exp. Med. 2005, 202, 1261-1269. [CrossRef]

27. Kim, S.-H.; Kim, K.-J.; Kang, H.J.; Son, Y.-J.; Choi, S.-W.; Lee, M.-J. The Dual Role of Oat Bran Water Extract in Bone Homeostasis Through the Regulation of Osteoclastogenesis and Osteoblast Differentiation. Molecules 2018, 23, 3119. [CrossRef]

28. Kim, K.-J.; Yeon,J.-T.; Choi, S.-W.; Moon, S.-H.; Ryu, B.J.; Yu, R.; Park, S.-J.; Kim, S.H.; Son, Y.-J. Decursin inhibits osteoclastogenesis by downregulating NFATc1 and blocking fusion of pre-osteoclasts. Bone 2015, 81, $208-216$. [CrossRef]

29. Rozen, S.; Skaletsky, H. Primer3 on the WWW for general users and for biologist programmers. Methods Mol. Boil. 2000, 132, 365-386.

30. Livak, K.J.; Schmittgen, T.D. Analysis of relative gene expression data using real-time quantitative PCR and the 2(-Delta Delta C(T)) Method. Methods 2001, 25, 402-408. [CrossRef]

31. Kim, H.; Kim, K.J.; Yeon, J.T.; Kim, S.H.; Won, D.H.; Choi, H.; Nam, S.J.; Son, Y.J.; Kang, H. Placotylene A, an inhibitor of the receptor activator of nuclear factor-kappaB ligand-induced osteoclast differentiation, from a Korean sponge Placospongia sp. Mar. Drugs 2014, 12, 2054-2065. [CrossRef] [PubMed]

32. Johnell, O.; Kanis, J.A. An estimate of the worldwide prevalence and disability associated with osteoporotic fractures. Osteoporos. Int. 2006, 17, 1726-1733. [CrossRef] [PubMed]

33. Harvey, N.; Dennison, E.; Cooper, C. Osteoporosis: Impact on health and economics. Nat. Rev. Rheumatol. 2010, 6, 99-105. [CrossRef] [PubMed]

34. Cauley, J.A. Public Health Impact of Osteoporosis. J. Gerontol. A Boil. Sci. Med. Sci. 2013, 68, $1243-1251$. [CrossRef] [PubMed]

35. Oka, Y.; Iwai, S.; Amano, H.; Irie, Y.; Yatomi, K.; Ryu, K.; Yamada, S.; Inaqaki, K.; Oquchi, K. Tea polyphenols inhibit rat osteoclast formation and differentiation. J. Pharmacol. Sci. 2012, 118, 55-64. [CrossRef] [PubMed]

36. Londzin, P.; Siudak, S.; Cegieła, U.; Pytlik, M.; Janas, A.; Waligóra, A.; Folwarczna, J. Phloridzin, an Apple Polyphenol, Exerted Unfavorable Effects on Bone and Muscle in an Experimental Model of Type 2 Diabetes in Rats. Nutrients 2018, 10, E1701. [CrossRef]

37. Feng, Y.L.; Jiang, X.T.; Ma, F.F.; Han, J.; Tang, X.L. Resveratrol prevents osteoporosis by upregulating FoxO1 transcriptional activity. Int. J. Mol. Med. 2018, 41, 202-212. [CrossRef]

38. Wang, X.; Batubara, I.; Yamauchi, K.; Mitsunaga, T. Identification and structure-activity relationship (SAR) of chemical constituents from Daemonorops draco (Willd.) Blume and selected commercial flavonoids on anti-osteoclastogenesis activity. Fitoterapia 2019, 138, 104280. [CrossRef]

39. Yao, W.; Zhang, H.; Jiang, X.; Mehmood, K.; Iqbal, M.; Li, A.; Zhang, J.; Wang, Y.; Waqas, M.; Shen, Y.; et al. Effect of Total Flavonoids of Rhizoma drynariae on Tibial Dyschondroplasia by Regulating BMP-2 and Runx2 Expression in Chickens. Front. Pharmacol. 2018, 9, 9. [CrossRef]

40. Adhikary, S.; Choudhary, D.; Ahmad, N.; Karvande, A.; Kumar, A.; Banala, V.T.; Mishra, P.R.; Trivedi, R. Dietary flavonoid kaempferol inhibits glucocorticoid-induced bone loss by promoting osteoblast survival. Nutrition 2018, 53, 64-76. [CrossRef]

41. Teitelbaum, S.L. Bone resorption by osteoclasts. Science 2000, 289, 1504-1508. [CrossRef] [PubMed]

42. Kang, K.-Y.; Hwang, Y.-H.; Lee, S.-J.; Kim, J.-J.; Nam, S.-J.; Yee, S.-T. Verification of the antioxidant activity of a subterranean part of Suaeda japonica Makino. Ind. Crop. Prod. 2017, 109, 836-842. [CrossRef] 
43. Herald, T.J.; Gadgil, P.; Tilley, M. High-throughput micro plate assays for screening flavonoid content and DPPH-scavenging activity in sorghum bran and flour. J. Sci. Food Agric. 2012, 92, 2326-2331. [CrossRef] [PubMed]

44. Grigoriadis, A.; Wang, Z.; Cecchini, M.; Hofstetter, W.; Félix, R.; Fleisch, H.; Wagner, E.F. c-Fos: A key regulator of osteoclast-macrophage lineage determination and bone remodeling. Science 1994, 266, 443-448. [CrossRef] [PubMed]

45. Mansky, K.C.; Sankar, U.; Han, J.; Ostrowski, M.C. Microphthalmia transcription factor is a target of the p38 MAPK pathway in response to receptor activator of NF-kappa B ligand signaling. J. Biol. Chem. 2002, 277, 11077-11083. [CrossRef] [PubMed]

46. Gingery, A.; Bradley, E.; Shaw, A.; Oursler, M.J. Phosphatidylinositol 3-kinase coordinately activates the MEK/ERK and AKT/NFkappaB pathways to maintain osteoclast survival. J. Cell Biochem. 2003, 89, 165-179. [CrossRef] [PubMed]

47. Wang, Y.; Harding, S.V.; Eck, P.; Thandapilly, S.J.; Gamel, T.H.; Abdel-Aal, E.-S.M.; Grow, G.H.; Tosh, S.M.; Jones, P.J.; Ames, N.P. High-Molecular-Weight beta-Glucan Decreases Serum Cholesterol Differentially Based on the CYP7A1 rs3808607 Polymorphism in Mildly Hypercholesterolemic Adults. J. Nutr. 2016, 146, 720-727. [CrossRef]

Sample Availability: Samples of the compounds are not available from the authors. 